\title{
Criminal Justice Involvement, Transition to Fatherhood, and the Demographic Foundation of the Intergenerational Transmission of Crime
}

PETER FALLESEN ${ }^{1,2}$, ORCiD ID: 0000-0003-0544-9977

${ }^{1}$ Swedish Institute for Social Research, Stockholm University, SE-106 91 Stockholm, Sweden.

${ }^{2}$ ROCKWOOL Foundation, Ny Kongensgade 6, DK-1472 Copenhagen C, Denmark

Word count: 7,333

Corresponding author: Peter Fallesen. Email. peter.fallesen@ sofi.su.se

\section{Funding}

This work was supported by the ROCKWOOL Foundation [1182]; and the Swedish Research Council for Health, Working Life and Welfare [2016-07099].

\section{Acknowledgement}

The author is deeply indebted to Lars H. Andersen for many discussions and numerous excellent suggestions, as well as to Arjan Blokland, Shawn Bushway, Bobby Apel, Linus Andersson, Frida Rudolphi, and colleagues at the LNU-group at the Swedish Institute for Social Research, Stockholm University for useful comments. Andreas M. Andersen provided valuable research assistance. Previous version presented at the American Society of Criminology Annual Meeting and at Stockholm University. 


\section{ABSTRACT}

\section{Objective}

Most analyses of the intergenerational transmission of criminal justice contacts compare outcomes of the second generation to the criminal history of the first generation. Ignoring the demographic process underlying transmission introduces selection bias into estimates insofar as the first generation's criminal history affects family formation and the probability of parenthood. We study how differential selection into fatherhood across criminal histories may affect prospective transmission of criminal justice convictions.

\section{Method}

We use administrative data on the complete fertility patterns and criminal justice history all Danish men born 1965-1973 and retrospective odds-ratio estimates of intergenerational transmission of criminal justice contacts to estimate prospective transmission of crime and the impact of differential fertility on cohort criminal justice involvement.

\section{Results}

Seriousness of criminal justice involvement is associated with earlier transition to fatherhood but ultimately higher levels of childlessness. The findings suggest that existing estimates of the intergenerational transmission of criminal justice contacts are overestimated at the population level.

\section{Conclusion}

Ignoring differential fertility across criminal justice history leads to upward-biased estimates of how criminal justice involvement is maintained across generations. Population level description of fertility trends has substantial implication for theoretical understanding of how transmission of offending occurs at the population level

\section{KEYWORDS}

administrative-data; family; fatherhood; intergenerational-transmission 
A growing body of literature considers the consequences of paternal conviction and incarceration for children (Andersen \& Wildeman, 2014; Geller, Garfinkel, \& Western, 2011; Wakefield, Lee, \& Wildeman, 2016; Wakefield \& Wildeman, 2013; Wildeman \& Andersen, 2017; Wildeman, Andersen, Lee, \& Karlson, 2014), with emphasis on the role of fathers' offending in explaining offspring offending (see Besemer et al. 2017; Wildeman 2020 for recent reviews). Focusing on how fathers' criminal activity impacts sons' criminal activity is informative from an epidemiological risk-factor perspective that seeks to address a specific person's risk of committing crime by considering their parental ancestry. Yet, such studies of father-to-son transmissions only provide parts of the full picture.

Parenthood is a necessary condition for any onward intergenerational transmission to occur. Whereas this statement at face value appears trivial, it has substantial and important implications for our understanding of the magnitude of intergenerational transmission (Song and Mare 2015). Differences in realized parenthood and number of children fathered between men with and without a history of criminal justice contacts can cause bias in estimates of how the criminal propensity of a first generation gets transmitted onwards to the next generation. Further, differences in unique number of fertility partners across criminal justice involvement may also point to important differences in type and intensity of father-child relationships that may also play a role in intergenerational transmission.

In this study, we provide descriptive evidence on differences in the timing and likelihood of having become at father at age 45 for ever- and never-convicted and -incarcerated Danish men. Using data on the full population of Danish men born 1965-1973 drawn from administrative demographic and criminal justice registers, as well as close-to-complete fertility data obtained from birth records, we describe the population-level association between men's registered criminal justice involvement, time of registered termination of criminal activities, and the timing and likelihood of transitioning to parenthood. We find that timing and prevalence of fatherhood differed across severity and timing of 
criminal justice contacts. Men with a history of criminal justice involvement transitioned earlier to fatherhood but ultimately also had lower probability of ever becoming fathers. The differential fertility across criminal justice histories means that retrospective estimates of intergenerational transmission likely are upward biased.

The study offers three contributions to the literature on the intergenerational transmission of crime. First, it uses high quality full population data to provide first evidence of how the risk of criminal justice convictions is maintained across generations at the population level. Second, the study demonstrates that not only do differences in the probability of obtaining fatherhood lead to selection bias, but differences in timing may also further increase transmission risk due to the strong agecomponent in life course pattern of offending (as also suggested by Lizotte et al. 2015). Third, it provides initial evidence on the size and direction of bias in retrospective estimates of transmission of criminal justice involvement and simulate counterfactual crime rates under scenarios where fertility rates are identical across criminal justice histories. In total, population level description of fertility trends has substantial implication for theoretical understanding of how transmission of offending occurs at the population level.

\section{INDIVIDUAL CRIMINAL HISTORY AND FATHERHOOD}

Criminal offending and criminal justice contact often concentrate in a subset of families (Farrington et al. 2001; e.g., Farrington, Barnes, and Lambert 1996) and along the male line (Farrington et al. 2001). Yet, the transmission of any form of social experience across generations is contingent on the second generation being born. Thus, both fertility and social transmission are necessary for intergenerational transmission to occur. Most studies of the intergenerational transmission of criminal justice involvement focus only on the social transmission by implicitly conditioning on parenthood in the 
transmitting generation through using retrospective data (see Besemer et al. 2017; Wildeman 2020 for recent reviews).

Whereas retrospective studies provide evidence on an individual level about risk factors for offending, recent work on social mobility and reproduction of status has demonstrated that ignoring the underlying demographic mechanisms of family formation leads to bias when trying to consider how social status and states are maintained across generations (e.g. Breen and Ermisch 2017; Lawrence and Breen 2016; Song and Mare 2015). Systematic differences in the probability of becoming a father and in the number of children men have across their criminal justice histories confound estimates of retrospective intergenerational transmission of crime, which could lead to erroneous conclusions on the strength of intergenerational transmission of criminal offending at the population level.

\subsection{Criminal Justice History and the Transition to Fatherhood}

Criminal justice convictions reflect lifestyle and serve as signals of (lack of) human capital to potential partners. These two components may affect fertility transition in opposite ways and at different points in the life course of men with histories of criminal justice involvement. A criminal history leads to decrease in human capital (Aizer and Doyle 2015; Western, Kling, and Weiman 2001) and serves as a signal to (potential) long-term partners of poor match quality (cf. Becker, Landes, and Michael 1977). At the same time, criminal involvement signals participation in a risky lifestyle that also is associated with early transition to fatherhood (e.g., van Roode et al. 2017). Thus, these two sets of influences likely affect the probability of transition to fatherhood for men with a history of criminal justice involvement in countervailing ways, differently at different points in the life course, and differently depending on the intensity of the criminal history. 


\subsubsection{Risky lifestyle and early fatherhood}

Male offenders have higher risk of early fatherhood compared to other men (Schoon and Mullin 2016).

The association between criminal involvement and early parenthood may reflect an underlying confounder of general risky lifestyle choices, which ultimately leave men with a history of criminal justice convictions and incarcerations to do worse on the relationship market (Fallesen and Andersen 2017; e.g., Zoutewelle-Terovan et al. 2016). Thus, men with a history of offending may simply transition to fatherhood earlier (a tempo effect) due to risky behavior when younger. However, they do not necessarily end up with a higher number of children (a quantum effect) because (a) potential and present partners view them as less desirable long term partner choices; or (b) criminal justice involvement signals that they are a poor match leading to increased risk of union dissolution among those who do form a union (Zoutewelle-Terovan et al. 2016). Further, the risk of union dissolution increases if the men experience incarceration (e.g., Comfort 2007; Fallesen and Andersen 2017; Wakefield and Andersen 2020) — even when incarceration spells are short (Fallesen and Andersen 2017). Ultimately, men with criminal justice contacts may transition to fatherhood at younger ages, but also have more unstable relationship trajectories, with instability increasing with severity of contacts with the criminal justice system.

\subsubsection{Criminal justice history as signal to potential fertility partners}

A personal history of criminal justice involvement affects attractiveness as father choice insofar as potential fertility partners look for stable individuals with good earnings capacity with whom to form a childbearing union. In the classical terms formulated by Becker (Becker 1973), individuals voluntarily engage in partnership when the expected utility of doing so supersedes the expected utility of remaining single. Ongoing criminal activity lowers the likelihood of employment (Loughran, Nagin, 
and Nguyen 2017), and also casts a shadow even after termination of criminal behavior (e.g., Pager 2003), thus lowering men with a criminal justice histories' perceived value as potential partners on the relationship market.

Although a simplified framework, Becker's approach highlights that people only invest in relationships when they believe the payoff of doing so is higher than the potential future gains from remaining single and continuing the search for a potential better partner. Further, children is understood as "relationship specific capital (Becker et al. 1977)" with substantial value inside the union, but valued less among outside options if the union ends. Here we assume that realized fertility is preconditioned on the union being formed. ${ }^{1}$ Men may also father children without being in a union with the mother. Within the taxonomy of the present study this do, however, fall under the guises of expression of a risky lifestyle.

Persistent, heavy involvement in criminality may ultimately lead to lower likelihood of ever becoming a father (Huschek and Blokland 2016), because potential romantic partners may perceive relationships with such men as a poor investment, especially if the involvement in criminality remains ongoing. Thus, age at termination of a criminal trajectory likely have impact not only on human capital [more work experience can accumulate when individuals do not commit crime (Loughran et al. 2017)], but also on signals send to society at large and to potential partners of having left a criminal past behind (Bushway and Apel 2012). Here, one most however consider the causal ordering of events. Life course criminology has argued for parenthood in general, and fatherhood in particular, as turning points leading to desistance and ultimately termination of criminal behavior (e.g. Sampson and Laub 2003). It

\footnotetext{
${ }^{1}$ Some women forego marriage, but chose children, for example in the absence of suitable husbands or enough available resources (Edin and Kefalas 2011). In this study we, however, focus solely on fatherhood and assumes some degree of union at conception although this is an oversimplifying assumption.
} 
is difficult to provide causal evidence on the link between fatherhood and criminal desistance and termination due to the nonrandom nature of parenthood. Yet, some have argued that at least in a Nordic context, termination tends to predate fatherhood (Monsbakken, Lyngstad, and Skardhamar 2013), indicating that men are more likely to desist because they are ready to transition into more prosocial roles, instead of desisting because a new role is thrust upon them.

\subsection{Selection and Transmission Mechanisms}

Fathers and sons are likely to share environment. Some environments may be more conducive to criminal offending than others, and especially persisting offenders may live in more conducive ones (Kirk 2018; Sharkey, Torrats-Espinosa, and Takyar 2017). Growing up alongside a criminal father in a community without prosocial norms (Buonanno, Montolio, and Vanin 2009; Mehlkop and Graeff 2010) and with an absence of capable guardians and prosocial peers (Buonanno et al. 2009; Cohen and Felson 1979) may impart a higher tendency towards criminality regardless of the father's own criminal history.

Fathers may also directly impart propensity for criminality on their offspring through rolemodelling (Farrington 2011). Empirical evidence also supports the idea that fathers in and of themselves matter. Early fatherhood is linked to higher rate of transmission of offending (Lizotte et al. 2015). Also, Hjalmarsson and Lindquist (2013) show that absent biological fathers transmit less criminal propensity than adoptive fathers and present biological fathers do. Further, intensity of father's criminality also matters. Incarceration causally increases risk of offspring being charged with a crime (Wildeman and Andersen 2017), and the strength of the intergenerational relationship between fathers and sons is increasing with paternal criminal activity (Hjalmarsson and Lindquist 2012). 
So, prior work suggests that on the one hand, the longevity and severity of men's criminal involvement likely increase their risk of fathering children early in the life course. On the other hand, severity and longevity decreases the likelihood of finding a steady partner, which may ultimately result in higher degree of childlessness among those who did not transition early in the life course. Similarly, severity of offending history appears to increase transmission, yet at the same time it also increases risk of union dissolution, thereby limiting fathers' day-to-day interaction with their children. Thus, beyond men's transition to fatherhood, we also consider timing of fatherhood, as well as number of unique fertility partners across the childbearing career to study the confounding factors of young age at fatherhood and likelihood of lower involvement with offspring. To capture longevity and severity of men's criminal justice histories, we consider age at termination of criminal trajectory and whether there ever was any incidences of incarceration.

\section{DATA}

To study transitions to parenthood and further parities across age and criminal justice involvement for Danish men, we link data from the Danish fertility and birth registries to data on criminal convictions and incarcerations. The fertility data covers all individuals born after 1973, as well as all individuals born from 1942 and onwards who remained alive and in Denmark after January 1, 1979. Data is close to complete for all cohorts born 1956 and onwards given the low level of early age mortality in Denmark (Knudsen 1998). The fertility data contain unique personal identifiers for children and their parents, with a very high level of reliability (Statistics Denmark 2017). From the fertility database, we include all men born in Denmark in the period 1965-1973, who will be our sample of individuals of interest. In total, we consider 354,354 men. We include 1965 at the oldest cohort, because this is the first cohort where we have complete data on criminal convictions from age 15 and onwards. We 
include 1973 as the youngest cohort because this is the last cohort we can follow in terms of fertility and criminal convictions until age 45 . We then link the 1965-1973 cohorts to the children born to them using the fertility database, only including life births. We right-censor men in the data at the following events: death, first emigration, and turning 45 years of age. We treat twin births as double births at the same time for measuring number of children fathered.

From the Danish crime registry, we obtain linkable information on all criminal convictions (excluding traffic violations) and all prison sentences of a length of seven days or longer for the period 1980-2018 (see Andersen, 2018b for description of the data). From the criminal registry we also obtain age at time of last committed crime that led to a conviction before turning 45 years of age. We impose the lower bound of seven days on incarceration spells to disregard short jail spells following an arrest. The Danish context is generally characterized by short sentences, with an average sentence length of less than a year for convictions that lead to incarceration ${ }^{2}$ and a median incarceration length of less than 90 days $^{3}$. Anyone with at least one sentence of seven days of incarceration or more is grouped as ever incarcerated.

We further divide those convicted into youth-limited and persisting offenders depending on whether they committed any criminal act leading to conviction after turning 21, or whether their known offending was limited to adolescence. Whereas the 21 st birthday is a somewhat arbitrary cutoff, it does in broad terms coincide with the beginning of decline the age-crime curve when crime is captured as criminal justice convictions, ${ }^{4}$ and partly informed by the taxonomy suggested by Moffitt (1993). In

\footnotetext{
${ }^{2}$ http://statistikbanken.dk/STRAF49.

${ }^{3} \mathrm{http}: / /$ statistikbanken.dk/STRAF47.

${ }^{4}$ https:// statistikbanken.dk/STRAF40.
} 
total, our choices on how to characterize criminal actions and age at last criminal act that led to conviction leave us with five distinct groups as seen from Figure 1.

[Figure 1 about here.]

\section{ANALYTICAL STRATEGY}

To estimate how differential fertility affects estimates of intergenerational transmission, and in turn what the crime rate would have been if all men had similar fertility rates, we need two main pieces of information. First, we need to know the contrafactual number of children men with criminal justice histories would have had, had they similar fertility rates as law-abiding men. Second, we need to know how many of the sons born to offenders would offend relative to sons born to law-abiding men. In other words, we first need information on the underlying demographic foundation, and then we need information on the intergenerational transmission under the counterfactual state of similar fertility rates. ${ }^{5}$

\subsection{The Demographic Foundation for Intergenerational Transmission}

To study how cohort fertility differs across men's criminal justice history we follow the approach used in Jalovaara et al.'s (2019) study of fertility differences across education. We first calculate probability of ever becoming a father at age 45 across criminal justice history, and then the average number of children fathered at age 45 , also across criminal justice history. We refer to the latter measure as the completed cohort fertility because only a negligible number of men father children after turning 45 .

Together, these two measures allow us to judge whether differences in completed cohort fertility is due

\footnotetext{
${ }^{5}$ Or, more precisely, the potential counterfactual fertility rates because fertility rates may be constant across criminal justice history.
} 
to differences in the share of each group of men who become fathers, or differences in the number of children fathers in each group have.

To also take timing of fatherhood into account, we estimate Kaplan-Meier (KM) failure curves for each group across ages 15-45, right-censoring those men who at 45 had not yet become fathers. Failure here refers to becoming a father. Because the model type often is used to estimate failure of machinery, death, or the occurrence of some sort of disease, the term failure is used. We keep the standard terminology, while remaining aware that (hopefully) for most men, becoming a father is not a failure. We treat men who at age 45 are still not fathers as right-censored in the data. The KM estimator is a nonparametric estimator of the form:

$$
\hat{S}(a)=\prod_{j \mid a_{j} \leq a}\left(\frac{n_{j}-d_{j}}{n_{j}}\right)
$$

where $\hat{S}(a)$ is the survival function of a man having 'survived' as childless until end of age $a, n_{j}$ is the number of men who at the beginning of time $a_{j}$ are still childless, and $d_{j}$ are the number of men who become fathers at time $a_{j}$. Given that our interest is in the timing of fatherhood, we instead estimate the failure function, which simply is defined as $\hat{F}(a)=1-\hat{S}(a)$ separately for each of the five type of men outlined in figure 1. Because we study the full universe of Danish men born 1965-1973, we delegate standard errors to appendix for ease of interpretation of the KM curves. To study the timing of cohort fertility until completion defined as age 45, we calculate the following measure:

$$
\operatorname{CFR}(a)=\frac{\sum_{j=0}^{a} d_{j}}{n}
$$


where $\operatorname{CFR}(a)$ is the average number of children born to a man at age $a, d_{j}$ is the number of children born between age $a$ and age $a-1$, and $\mathrm{n}$ is the number of fathers. Because the data cover all men of interest, and we can calculate fathers age at the day level, we dispense with standard errors.

\subsection{The Implication of Differential Fertility for Intergenerational Transmission}

To study the role the differences in fertility rates across criminal justice histories, our components of interest is: a) how many male offspring with criminal convictions we can expect men with criminal justice conviction to father relative to how many they would father, had men with criminal justice convictions exhibited similar cohort fertility rates as men without histories of criminal justice convictions; b) what the corresponding crime rate among the second generation would be if men with histories of criminal justice convictions had similar fertility to men without criminal histories; and c) how does the estimate of the intergenerational transmission of crime change when we apply a prospective approach. For the first two components, we will assume no selection into fatherhood within the groups of men with and without criminal histories. This assumption is likely unfeasible. However, if sorting into fatherhood generally occurs more through the human capital channel sketched out above than through the risk behavior channel, and if female fertility partners on average select partners within each group who have higher prosocial capital (and thus, will be less likely to transmit offending across generations compared to the men not selected for fatherhood), our estimates of both components of interest will be conservative.

For the sake of simplicity, we first divide the sample into only two categories: 1) men who ever have received a criminal justice conviction; and 2) men who never have received a criminal justice conviction. This provides an estimate for a situation where the transmission of criminal justice convictions is identical for all levels of men's criminal justice contact-that is, youth-limited offenders 
and persisters transfer criminality to the same degree. Given that youth-limited offenders have fertility rates essentially identical to men who never receive a criminal justice conviction, this will lead to a lower bound estimate of how much retrospective estimates underestimate intergenerational transmission. We also perform an estimation for a situation where youth-limited offenders (who mainly terminate their criminal trajectory prior to fatherhood) have sons who are only as likely to offends as the sons of men without any criminal history. Given that this grouping singles out the persisters as the sole carriers of the intergenerational transmission of crime, and because persisters have substantial lower average observed fertility, this calculation will likely provide an upper bound estimate.

As the starting point, we first need to obtain estimates of retrospective transmission of criminal offending to obtain the probability that a son will ever receive a criminal justice conviction conditional on his father ever receiving one. We rely on two sets of retrospective estimates of the intergenerational transmission of offending: Hjalmarsson and Lindquist (2012) and Besemer et al. (2017). Hjalmarsson and Lindquist (2012) provides the odds ratio of the estimate of the association between father's criminal conviction and son's criminal conviction for Sweden, a neighboring and to a large extent similar country to Denmark in terms of criminal activity and punishment (Pratt 2007), fertility (Hellstrand et al. 2021), and welfare state arrangements (Kvist et al. 2011). Hjalmarsson and Lindquist estimate the odds ratio for the retrospective $(R)$ intergenerational association at the extensive margin to be $O R^{R}=2.06$. Besemer et al. (2017) provides a meta-analysis of the intergenerational transmission of criminal behavior from a broader set of countries, and find an unadjusted $O R^{R}=2.40$. The odds ratio for the association between father and son's criminal convictions $\left(O R_{I C}^{R}\right)$ is defined as:

$$
O R_{I C}^{R}=\frac{\frac{P_{C}}{1-P_{C}}}{\frac{P_{L}}{1-P_{L}}}
$$


where $P_{C}$ is the probability of a son having a criminal justice conviction (at age 30) conditional on father having received a criminal justice conviction and $P_{L}$ is probability of a son having a criminal justice conviction (at age 30) conditional on father having not received a criminal justice conviction It follows that $1>P_{C}>P_{L}>0$. The odds ratio remains the same for different set of values of probabilities if the relative relationship between the odds stays the same. Hjalmarsson and Lindquist (2012) provide some validation for the odds ratio remaining close to constant at least for different parts of the life course: their paper also provides odds ratio for the intergenerational association in juvenile delinquency, which they find to be $O R^{R}=2.13$, so similar in relative magnitude to the OR for criminal justice convictions. By (a) assuming that the odds ratio remains constant; (b) knowing the probability of having a father who have had criminal justice contact; and (c) the share of men in society who ever receives a conviction, we can recover $P_{C}$ and $P_{L}$ and from there provide an prospective estimate of the reproduction of criminal offending across generations. The average share of sons with a criminal justice conviction, $S$, can be written as the weighted shares of son's crime $(P)$ conditional of father's criminal justice history $(F)$ :

$$
S=P_{C} * F_{C}+P_{L} *\left(1-F_{C}\right)
$$

We also consider expected and counterfactual results from the scenario where men who desist their criminal activity before turning 21 does not transmit their criminal conviction unto the next generation. That is, the intergenerational transmission of criminal conviction is driven solely by the persisters (the most criminal active). This is identical to expanding equation 2 to:

$$
\begin{aligned}
S & =P_{C} * F_{C}+P_{L} *\left(1-\mathrm{F}_{\mathrm{C}}\right) \\
& =P_{C^{*}} * F_{C 2}+P_{L} * F_{C 1}+P_{L} *\left(1-\mathrm{F}_{\mathrm{C} 2}-F_{C 1}\right) \\
& =P_{C^{*}} * F_{C 2}+P_{L} *\left(1-\mathrm{F}_{C 2}\right)
\end{aligned}
$$

where $P_{L}$ remains unchanged, $F_{C 1}$ is the share of fathers who desist before $21, F_{C 2}$ is the share of fathers who persist after their 21 st birthday, and $P_{C^{*}}$ is the probability that sons of fathers who persist 
receive a criminal conviction before turning 30. Under this version of the counterfactual scenario, desisting men's fertility are weighted up to the same level as non-convicted men and their expected and counterfactual sons' risk of ever receiving a conviction is assumed identical to sons of non-convicted men as well. We also weigh the fertility of men who persists up to the level of men who never receive a conviction and assume that both expected and hypothetical sons have a risk of conviction before age 30 equal to $P_{C^{*}}$.

\section{RESULTS}

In this section we first present descriptive evidence on the fertility differences across criminal histories of all Danish men born 1965-1973, the only cohorts for which we have completely criminal justice histories from age 15 and onwards and who have turned 45. We then use these differences to estimate how crime rates may look absent fertility differences across criminal justice histories. Last, we compare retrospective odds ratio estimates to prospective odds ratio estimates to demonstrate how differential levels of fertility play a substantial role in shaping the onward transmission of crime across society.

\subsection{Men's Criminal Justice History and Fertility}

Figure 2 describes the Kaplan-Meier curves for transitioning to parenthood for men from age 15 to age 45 across their history of criminal justice involvement. Table 1 shows the distribution of conviction and incarceration histories across the cohort, as well as the ultimate share who ever become fathers, the median age at fatherhood, and the total number of children fathered at age 45 . Only 5.5 percent of the men ever experience an incarceration spell of more than seven days, and almost all of them continue to receive convictions after turning 21. Among the birth cohorts included, more than 26 percent of all men received at least one conviction at age 45 , and 20 percent received their last conviction after turning 21 . 
[Figure 2 about here.]

[Table 1 about here.]

For the group of Danish men that never received a criminal conviction, 75 percent had become fathers at age 45, with the median age of first-time fatherhood being 29.8 years of age (see Table 1) for those who became fathers. Among those who received their last criminal conviction after turning 21 less than 70 percent had transitioned to fatherhood at age 45 unconditional on whether they ever had been incarcerated or not. The persisters differed on timing of transition to fatherhood, with median age of first-time fatherhood being 26.6 years for the serious persisters, and 28.5 years for the low-level persisters. Low-level youth offenders had fatherhood transition-probabilities like men without a history of criminal justice contacts, but transitioned at an earlier age, with the median age for becoming a father for the first time being 28.7 years. We find the largest likelihood of fatherhood among serious youth offenders - 77 percent of this group had become fathers at age 45 , although this estimate has wide standard errors and is not significantly different from law-abiding men and low-level youth offenders (see Figure A1 in appendix). Thus, youth limited offenders were equally likely to become fathers as men who never received a conviction, but youth limited offender did so earlier in the life course on average. Initially, serious youth offenders have age-fatherhood profiles similar to serious persisters. Nevertheless, where the serious persisters fatherhood probability began levelling off in their late 20ies, the serious youth offender only began levelling off on their increase in cumulative transition probability in their early 30ies. Timing of desistance and termination affected the likelihood of transitioning to parenthood for men, with youth-limited offenders transitioning earlier and more to fatherhood than men without a history of criminal justice contacts did. Persistence and type of criminal justice contacts were associated both with the timing and likelihood of men's transition to fatherhood. 
Next, we turn the attention to the number of children men father on average conditional on their history of criminal justice contacts. Figure 3 reports the completed cohort fertility for the 1965-1973 cohort of men across the men's history of criminal justice involvement. The figure shows a similar pattern as figure 2. Men who received convictions after turning 21 had on average fewer children, with serious persisters having on average the lowest number of children at around 1.4 child. Youth-limited offenders and men without a history of convictions also had similar number of children at age 45, at 1.6 child for each group. Thus, those least likely to become fathers also had on average the fewest children.

Table 2 reports the average number of children for each group conditional on fatherhood. Among men who became fathers, differences in the average number of children across history of criminal justice involvement are much more muted - fathers who persisted and had a history of incarceration had on average only $4 \%$ percent fewer children than had fathers without any history of criminal justice convictions. Thus, the main difference in cohort fertility across the groups is driven by entry into fatherhood, not by differences in how many children men who become fathers had.

[Table 2 about here.]

Table 2 further report the number unique partners that fathers in each group had children with. Here we see at starker difference with all groups with a history of criminal justice convictions having on average a higher number of unique partners. Whereas the average father without any criminal justice conviction had 1.10 unique partners, fathers who persisted and had a history of incarceration had on average 1.36 unique partners - a 24\% difference. So, whereas men with more persistent criminal justice histories had lower likelihood of becoming fathers and had lower completed cohort fertility, those who became fathers did so at a younger age, fathered a similar number of children, and had higher rates of multiple partner fertility. 


\subsection{The Implication of Differential Fertility for Estimates of Intergenerational Transmission}

In this section, we calculate an approximation of the prospective transmission of criminal justice convictions in Denmark and compare these to approximated retrospective estimates. Because the estimates of intergenerational association from Hjalmarsson and Lindquist (2012) is measured at age 30, we also measure the average share of sons with a criminal justice conviction, $(S)$, at that point. The most recent Danish birth cohort whose convictions can be followed to end of age 29 is the 1988 cohorts. At the end of 2018, $19.0 \%$ of males in that cohort had received at least one conviction under penal law. ${ }^{6}$ Yet, the oldest men in the cohort fertility sample were only 25 in 1988, so many of them had still not become fathers (as seen in figure 2). Further, the share of recent birth cohorts who are ever convicted or charged with a crime has substantially declined, including among those not yet 30 years of age (Andersen, Anker, \& Andersen, 2016). To reflect this development and more adequately match fathers to the cohorts of their potential sons, we extrapolate the cumulative share of men ever convicted for more recent birth cohorts by assuming that the relative difference between the cumulative rate at age 20 (25) for men born 1998 (1993) and the cumulative rate for men born in 1988 will remain the same until age $30 .^{7}$

The different shares of sons $(S)$ ever convicted across birth cohorts are shown in Panel A in table 3 together with the odds ratio for the intergenerational association of offending and the share of fathers who are ever (never) convicted. From table 1 , we can calculate the share, $F_{C}$, of sons who can expect to have a father who have received a criminal justice conviction (assuming identical gender distribution in offspring across fathers' criminal justice conviction status) to be equal to .26. To obtain values for $P_{L}$

\footnotetext{
${ }^{6} \mathrm{http} / / /$ statistikbanken.dk/STRAFFO1

${ }^{7} \mathrm{http} / / /$ statistikbanken.dk/STRAFFO1
} 
and $P_{C}$, we further need an estimate for the share of sons who ever receives a criminal justice conviction, $S$.

In Table 3, we assume that the intergenerational transmission of criminal justice convictions is identical across men's level of criminal involvement. That is, in this scenario the transfer of ever committing crime is independent of age at termination of criminal behavior and intensity of criminality. Because men who persist into the twenties have lower fertility rates than youth-limited offenders, and intensity likely increase transmission (Hjalmarsson and Lindquist 2012; Wildeman and Andersen 2017), this means that our counterfactual scenario probably represents a lower bound estimate of the role differential fertility plays in shaping how crime is transmitted across generations.

[Table 3 about here.]

Panel B reports the derived probabilities of a son ever receiving a conviction at age 30 , derived from the information in panel A and using equation 2. See appendix B for an example of a derivation for the 1988 birth cohort. Based on Hjalmarsson and Lindquist's more conservative estimate, for the 1988 birth cohort we would expect $28 \%$ of all sons born to fathers ever convicted at age 45 to have received a criminal justice conviction at age 30 , whereas we would expect $16 \%$ of sons born to never convicted fathers to have received a conviction at age 30 . The estimate of intergenerational transmission provided by Besemer et al. (2017) instead suggests that for the 1988 cohort, 30 percent of sons born to convicted fathers receive a conviction before age 30, whereas only 15 percent of sons born to non-convicted fathers ever receive a conviction before age 30 .

In panel $\mathrm{C}$, we calculate how many convicted and non-convicted sons men with and without a conviction history could expect to have. We also present results from the counterfactual scenario where convicted men had non-convicted men's cohort fertility rate. We assume a 50/50 gender split in whether men have sons or daughters when they have children. For the 1998 cohort of sons, and using 
the $\mathrm{OR}^{\mathrm{R}}$ provided by Hjalmarsson and Lindquist (2012), we would expect 1,781 more convicted sons had convicted men had the same fertility rates as non-convicted men. At the same time, we would also expect 4,578 more non-convicted sons. In total, as shown in Panel D, this would be an increase of 3.4 percent in the number of convicted sons in society and a 2.0 percent increase in the number of nonconvicted sons. Such an increase results in a 1.1 percent increase in the share of sons ever convicted in a birth cohort from .190 to .192 . That increase would in return have resulted in 2.7 criminal convictions more per 1,000 sons if we assume that these hypothetical criminal sons received the same number of convictions as their non-hypothetical peers did. ${ }^{8}$ Results from the extrapolated 1993 and 1998 cohorts show smaller absolute differences between the expected and the counterfactual scenario (which is expected due to the declining overall share of men to ever receive a conviction), but also increasing relative differences.

Table 3 also reports the results using the retrospective odds ratio provided by Besemer et al. (2017) $\left[\mathrm{OR}^{\mathrm{R}}=2.40\right]$, indicating a higher degree of transmission of criminal behavior than found by Hjalmarsson and Lindquist (2012). Table 3 reports that for the 1988 cohort, we could expect 1,907 extra sons that would have received a conviction before age 30 (a $3.6 \%$ increase), and an additional 4,450 non-convicted sons (a $2.0 \%$ increase). The share of the 1988 cohort with a conviction at age 30 would increase with 1.3 percent to .192, implying an additional 3.2 criminal acts per 1,000 sons under the same assumptions as above.

Table 4 reports expected and counterfactual results from the scenario where men who desist their criminal activity before turning 21 does not transmit their criminal conviction unto the next generation, building on the extension seen in equation 3. That is, the intergenerational transmission of criminal

\footnotetext{
${ }^{8}$ Information on number of convictions for the birth cohort obtained from http://statistikbanken.dk/STRAFFO1.
} 
conviction is driven solely by the persisters (the most criminal active). Panel B reports the expected probability of a son to have received a conviction conditional of paternal criminal justice history. Under the assumption that all transmission carries through fathers who persist, one-in-three sons born to persisters in 1988 is expected to receive a conviction before turning 30. Under the hypothetical scenario of equal fertility rates across criminal justice history and using the retrospective $O R^{R}$ of 2.06 as starting point, we could expect an additional 2,045 sons with a conviction at age 30 (a 3.9\% increase) and 4,314 additional sons without a conviction (a 1.9\% increase). The share of sons ever convicted would increase to .193 , which would be an increase of 1.6 percent, corresponding to an additional 3.9 more criminal acts per 1,000 sons born in 1988. Under the higher estimate of intergenerational transmission provided by Besemer et al., would under the counterfactual scenario expect 2,234 additional sons with a conviction before age 30 (4.2\% increase), and 4,124 more non-convicted sons. This lead the share of sons ever convicted at age 30 to increase with 1.9 percent to .194 , corresponding to 4.7 additional crimes per 1,000 sons born in 1988. Results from the extrapolated 1993 and 1998 cohorts show smaller absolute differences between the expected and the counterfactual scenario (which is expected due to the declining overall share of men to ever receive a conviction), but also increasing relative differences between the expected and counterfactual scenario.

[Table 4 about here.]

Finally, Table 5 reports two sets of prospective odds ratios for the intergenerational transmission of crime. First, the prospective OR for all men who ever father a child. Compared to the retrospective odds ratio, this measure considers differences in number of children between men with and without criminal justice convictions, conditional on these men becoming fathers. Second, the prospective odds ratio for intergenerational transmission of criminal convictions for all men. Compared to the retrospective odds ratio, this measure account for both the difference in number of children among men 
who become fathers, as well as the difference in probability of entering fatherhood. For the 1988 cohort of sons, we see only a very small difference in retrospective and prospective odds ratio when using the prospective odds ratio that only includes fathers (2.06 vs. 2.03). Thus, as also suggested by Table 2, differences in number of children among fathers across criminal justice history plays little to no role in how crime is transmitted across generations in Denmark.

[Table 5 about here.]

When we instead compare the retrospective odds ratio to the prospective odds ratio for all men, which mean comparing the estimate of risk for 'inheriting' the criminal conviction of one's father to the risk that men pass on criminal convictions to a following generation, we see larger differences. The prospective estimate for the transmission of criminal convictions from men to a son is $1.78,24$ percent smaller than the retrospective estimate. As the share of sons ever convicted declines as younger cohorts generally exhibit a crime decline (Columns 2 and 3, Panel B in Table 3 and 4), we see the prospective estimate for all men move closer to the retrospective estimate. That is, when criminal convictions in the second generation becomes rarer, the 'bias' due to differential fertility for retrospective estimates becomes smaller, if we can assume a stable relative difference in crime rates between sons of convicted fathers and sons of never convicted father. Thus, retrospective estimates of intergenerational transmission of crime overestimate the transmission of crime from one generation to the next at the population level, as long as men with a history of criminal justice conviction have lower fertility rates than men without a history of criminal justice convictions.

\subsection{Limitations of Findings}

The above presented research rests on a set of strong explicit and implicit assumptions. We have aimed to make the explicit assumptions clear above, but here we will discuss the more implicit assumptions 
made by our approach. First, the data used comes from administrative population registers and thus represent an administrative reality that might not correspond perfectly to peoples' lived lives. For the fertility data, this is likely of little concern, because the data captures close to all fathers and several safeguards are in place to secure precise assignment of paternity. When it comes to crime, the data is likely far less complete, because some, if not most, criminal actions are never assigned a guilty party, and other never even reported or discovered. Here, we have instead hinged our study on the assumption that people who continuously commit crime are more likely to be convicted. It is also therefore that we have used age at registered termination of criminal activities and experiences of incarceration as our measures of criminal intensity instead of tallying criminal acts or considering their severity (beyond leading to incarceration).

Second, society is in the process on an ongoing crime decline, which at least for Denmark appears to happen at the extensive margin (Andersen et al., 2016). The decline may have implications for the magnitude of the intergenerational transmission of crime that are yet to be fully grasped. Whereas this would not affect the overall argument made in this paper, it could have substantial implications for the magnitude of the difference between retrospective estimates and prospective estimates, especially because this study includes an older cohort of men and because Denmark presently is undergoing a decline in fertility rates that is still unfolding (Comolli et al. 2021; Hellstrand et al. 2021).

Last, as heavily documented in the literature, fatherhood does not happen in a vacuum, may be transformative, and may initiate desistance (Kerr et al. 2011). Mother's criminal behavior also matters (Hjalmarsson and Lindquist 2013), and there are strong evidence on assortative mating along lines of criminal involvement (e.g., Andersen, Andersen, and Skov 2015). All these important processes have not been thoroughly considered in this study, but future work should seek to incorporate these perspectives to paint a more detailed picture of how differences not only in fertility, but also in the 
family situation, are important for fully understanding intergenerational transmission at a population level.

\section{CONCLUSION}

The dynastic structure of criminal offending that underlies the intergenerational transmission of crime is contingent on an 'heir' to be born. In this study, we have considered how differences across criminal involvement in the probability of fatherhood and number of children men father may have substantial implications for our understanding of the intergenerational transmission of criminal behavior. We documented that the more intense a man's criminal justice contacts were across his life course (measured through age at desistance and whether he ever was incarcerated), the fewer children he would one average ever father. Further, men who persist offending into adulthood are less likely to ever become fathers, but those who do, do so at younger ages, where their criminal intensity likely still is higher and transmission risk likely amplified. We then demonstrated how the differences in number of children ever fathered across criminal justice histories can lead to bias in estimates of how the propensity for criminal justice contacts is transmitted across generations. The retrospective approach of regressing son's criminal history on father's criminal history ignored differences in fertility across criminal background. Under two different scenarios, we demonstrated how known retrospective estimates of intergenerational transmission implies higher crime rates than observed if differences in fertility is not considered. Last, we showed that prospective estimates of the intergenerational transmission are smaller than retrospective estimates, but also that the difference decreased as the share of a second-generation cohort who could expect to ever receive at least one criminal justice conviction decreased. The latter implied that if the great crime decline continues and the odds ratios for 
intergenerational transmission remains constant, retrospective estimates will become less biased over time.

\subsection{Perspective}

This study points to a possible additional explanation of the great and ongoing crime declinedifferential selection into fertility. If the intergenerational transmission process is truly causal and not simply confounded by other factors, as suggested by several pieces of recent research (e.g., Hjalmarsson and Lindquist 2013; Wildeman and Andersen 2017), then criminal men having fewer children than law-abiding men and at rates below population replacement levels could be a salient independent cause of the decline. In essence, it would be an explanation similar to the one posed by Donohue and Levitt $(2001,2019)$ but driven by a subtly different mechanism — where Donohue and Levitt point to access to abortion causing some children never to be born, here we instead suggests that selection out of fatherhood caused certain men to never become fathers. However, to fully study this would need data sources that covers a large population for most of the $20^{\text {th }}$ century and include information on both fertility, intergenerational links, and crime - data sources that at presently are not available.

\section{REFERENCES}

Aizer, Anna and Joseph J. Doyle. 2015. "Juvenile Incarceration, Human Capital, and Future Crime: Evidence from Randomly Assigned Judges.” Quarterly Journal of Economics 130(2):759-804. Andersen, Lars H. 2018. "Danish Register Data: Flexible Administrative Data and Their Relevance for Studies of Intergenerational Transmission." in Intergenerational continuity of criminal and antisocial behavior: an international overview of studies, edited by V. I. Eichelsheim and S. G. A. van de Weijer. Routledge. 
Andersen, Lars H., Anne Sofie Tegner Anker, and Signe H. Andersen. 2016. “A Formal

Decomposition of Declining Youth Crime in Denmark.” Demographic Research 35(1):1303-16.

Andersen, Signe H., Lars H. Andersen, and Peer E. Skov. 2015. "Effect of Marriage and Spousal

Criminality on Recidivism.” Journal of Marriage and Family 77(2):496-509.

Andersen, Signe H. and Christopher Wildeman. 2014. "The Effect of Paternal Incarceration on

Children's Risk of Foster Care Placement.” Social Forces 93(1):269-98.

Becker, Gary S. 1973. “A Theory of Marriage: Part I.” Journal of Political Economy 81(4):813-46.

Becker, Gary S., Elisabeth M. Landes, and Robert T. Michael. 1977. “An Economic Analysis of Marital Instability.” Journal of Political Economy 85(6):1141-87.

Besemer, Sytske, Shaikh I. Ahmad, Stephen P. Hinshaw, and David P. Farrington. 2017. “A Systematic Review and Meta-Analysis of the Intergenerational Transmission of Criminal Behavior.” Aggression and Violent Behavior 37:161-78.

Breen, Richard and John Ermisch. 2017. "Educational Reproduction in Great Britain: A Prospective Approach.” European Sociological Review 33(4):590-603.

Buonanno, Paolo, Daniel Montolio, and Paolo Vanin. 2009. "Does Social Capital Reduce Crime?” Journal of Law and Economics 52(1):145-70.

Bushway, Shawn D. and Robert Apel. 2012. “A Signaling Perspective on Employment-Based Reentry Programming: Training Completion as a Desistance Signal.” Criminology and Public Policy 11(1):21-50.

Cohen, Lawrence E. and Marcus Felson. 1979. "Social Change and Crime Rate Trends: A Routine Activity Approach.” American Sociological Review 44(4):588.

Comfort, Megan. 2007. "Punishment Beyond the Legal Offender." Annual Review of Law and Social Science 3(1):271-96. 
Comolli, C. L., G. Neyer, G. Andersson, L. Dommermuth, P. Fallesen, M. Jalovaara, A. Klængur Jónsson, M. Kolk, and T. Lappegård. 2021. "Beyond the Economic Gaze: Childbearing During and After Recessions in the Nordic Countries.” European Journal of Population 37(2):473-520.

Donohue, J. J. and S. D. Levitt. 2001. “The Impact of Legalized Abortion on Crime.” The Quarterly Journal of Economics 116(2):379-420.

Donohue, John J. and Steven D. Levitt. 2019. The Impact of Legalized Abortion on Crime over the Last Two Decades.

Edin, Kathryn and Maria Kefalas. 2011. Promises I Can Keep: Why Poor Women Put Motherhood before Marriage. University of California Press.

Fallesen, Peter and Lars H. Andersen. 2017. "Explaining the Consequences of Imprisonment for Union Formation and Dissolution in Denmark.” Journal of Policy Analysis and Management 36(1):15477.

Farrington, David P. 2011. "Families and Crime.” Pp. 130-57 in Crime and public policy, edited by J. Petersilia and J. Q. Wilson. Oxford University Press.

Farrington, David P., Geoffrey C. Barnes, and Sandra Lambert. 1996. "The Concentration of Offending in Families." Legal and Criminological Psychology 1(1):47-63.

Farrington, David P., Darrick Jolliffe, Rolf Loeber, Magda Stouthamer-Loeber, and Larry M. Kalb. 2001. "The Concentration of Offenders in Families, and Family Criminality in the Prediction of Boys’ Delinquency.” Journal of Adolescence 24(5):579-96.

Geller, Amanda, Irwin Garfinkel, and Bruce Western. 2011. "Paternal Incarceration and Support for Children in Fragile Families.” Demography 48(1):25-47.

Hellstrand, Julia, Jessica Nisén, Vitor Miranda, Peter Fallesen, Lars Dommermuth, and Mikko Myrskylä. 2021. "Not Just Later, but Fewer: Novel Trends in Cohort Fertility in the Nordic 


\section{Countries." Demography.}

Hjalmarsson, Randi and Matthew J. Lindquist. 2012. "Like Godfather, like Son: Exploring the Intergenerational Nature of Crime.” Journal of Human Resources 47(2):550-82.

Hjalmarsson, Randi and Matthew J. Lindquist. 2013. "The Origins of Intergenerational Associations in Crime: Lessons from Swedish Adoption Data.” Labour Economics 20:68-81.

Huschek, Doreen and Arjan Blokland. 2016. "Crime and Parenthood: Age and Gender Differences in the Association between Criminal Careers and Parenthood." Advances in Life Course Research 28:65-80.

Jalovaara, Marika, Gerda Neyer, Gunnar Andersson, Johan Dahlberg, Lars Dommermuth, Peter Fallesen, and Trude Lappegård. 2019. "Education, Gender, and Cohort Fertility in the Nordic Countries.” European Journal of Population 35(3):563-86.

Kerr, David C. R., Deborah M. Capaldi, Lee D. Owen, Margit Wiesner, and Katherine C. Pears. 2011. “Changes in At-Risk American Men’s Crime and Substance Use Trajectories Following Fatherhood.” Journal of Marriage and Family 73(5):1101-16.

Kirk, David S. 2018. "The Effects of Neighborhood Context and Residential Mobility on Criminal Persistence and Desistance.” Pp. 515-35 in The Oxford Handbook of Developmental and LifeCourse Criminology.

Knudsen, L. B. 1998. “The Danish Fertility Database.” Danish Medical Bulletin 45(2):221-25. Kvist, Jon, Johan Fritzell, Bjørn Hvinden, and Olli Kangas. 2011. Changing Social Equality: The Nordic Welfare Model in the 21st Century. Policy.

Lawrence, Matthew and Richard Breen. 2016. "And Their Children after Them? The Effect of College on Educational Reproduction.” American Journal of Sociology 122(2):532-72.

Lizotte, Alan J., Matthew D. Phillips, Marvin D. Krohn, Terence P. Thornberry, Shawn D. Bushway, 
and Nicole M. Schmidt. 2015. "Like Parent Like Child? The Role of Delayed Childrearing in Breaking the Link Between Parent's Offending and Their Children's Antisocial Behavior." Justice Quarterly 32(3):410-44.

Loughran, Thomas A., Daniel S. Nagin, and Holly Nguyen. 2017. "Crime and Legal Work: A Markovian Model of the Desistance Process." Social Problems 64(1):30-52.

Mehlkop, Guido and Peter Graeff. 2010. "Modelling a Rational Choice Theory of Criminal Action: Subjective Expected Utilities, Norms, and Interactions." Rationality and Society 22(2):189-222. Moffitt, Terrie E. 1993. "Adolescence-Limited and Life-Course-Persistent Antisocial Behavior: A Developmental Taxonomy.” Psychological Review 100(4):674-701.

Monsbakken, Christian Weisæth, Torkild Hovde Lyngstad, and Torbjorn Skardhamar. 2013. "Crime and the Transition to Parenthood the Role of Sex and Relationship Context." British Journal of Criminology 53(1):129-48.

Pager, Devah. 2003. “The Mark of a Criminal Record.” American Journal of Sociology 108(5):975.

Pratt, J. 2007. "Scandinavian Exceptionalism in an Era of Penal Excess: Part I: The Nature and Roots of Scandinavian Exceptionalism." British Journal of Criminology 48(2):119-37.

van Roode, Thea, Katrina Sharples, Nigel Dickson, and Charlotte Paul. 2017. "Life-Course Relationship between Socioeconomic Circumstances and Timing of First Birth in a Birth Cohort" edited by J. P. van Wouwe. PLOS ONE 12(1):e0170170.

Sampson, Robert J. and John H. Laub. 2003. "Life-Course Desisters? Trajectories of Crime among Delinquent Boys Followed to Age 70." Criminology 41(3):555-92.

Schoon, Ingrid and Annabel J. C. Mullin. 2016. “Crime Involvement and Family Formation: Evidence from the British Birth Cohort Study." Advances in Life Course Research 28:22-30.

Sharkey, Patrick, Gerard Torrats-Espinosa, and Delaram Takyar. 2017. "Community and the Crime 
Decline: The Causal Effect of Local Nonprofits on Violent Crime.” American Sociological Review 82(6):1214-40.

Song, Xi and Robert D. Mare. 2015. "Prospective Versus Retrospective Approaches to the Study of Intergenerational Social Mobility.” Sociological Methods \& Research 44(4):555-84.

Statistics Denmark. 2017. "Documentation of Statistics: Fertility Database - Statistics Denmark." Retrieved July 27, 2018

(https://www.dst.dk/en/Statistik/dokumentation/documentationofstatistics/fertility-database).

Wakefield, Sara and Lars H. Andersen. 2020. "Pretrial Detention and the Costs of System Overreach for Employment and Family Life." Sociological Science 7:342-66.

Wakefield, Sara, Hedwig Lee, and Christopher Wildeman. 2016. "Tough on Crime, Tough on Families? Criminal Justice and Family Life in America” edited by C. Wildeman, S. Wakefield, and H. Lee. Annals of the American Academy of Political and Social Science 665(1):8-21.

Wakefield, Sara and Christopher Wildeman. 2013. Children of the Prison Boom: Mass Incarceration and the Future of American Inequality. Oxford University Press.

Western, Bruce, Jeffrey R. Kling, and David F. Weiman. 2001. "The Labor Market Consequences of Incarceration." Crime \& Delinquency 47(3):410-27.

Wildeman, Christopher. 2020. "The Intergenerational Transmission of Criminal Justice Contact." Annual Review of Criminology 3:217-44.

Wildeman, Christopher and Signe H. Andersen. 2017. “Paternal Incarceration and Children's Risk of Being Charged by Early Adulthood: Evidence from a Danish Policy Shock.” Criminology $55(1): 32-58$.

Wildeman, Christopher, Signe H. Andersen, Hedwig Lee, and Kristian Bernt Karlson. 2014. "Parental Incarceration and Child Mortality in Denmark." American Journal of Public Health 104(3):428- 
33.

Zoutewelle-Terovan, Mioara, Victor van der Geest, Aart C. Liefbroer, and Catrien Bijleveld. 2016.

"The Influence of Criminal Offending on Union Formation and Union Dissolution for Disadvantaged Individuals." Advances in Life Course Research 28:31-40. 
TABLE 1 Distribution of criminal histories and fertility for all Danish men born 1965-1973

\begin{tabular}{|c|c|c|c|c|c|}
\hline & $\mathbf{N}$ & $\begin{array}{l}\text { Share of } \\
\text { Sample }\end{array}$ & $\operatorname{Pr}($ Fatherhood $=1)$ & $\begin{array}{l}\text { Median age, } \\
\text { fatherhood }^{\mathrm{a}}\end{array}$ & $\begin{array}{l}\text { Cohort fertility } \\
\text { rate }\end{array}$ \\
\hline Law-abiding or non-sanctioned & 256356 & 0.723 & 0.751 & 29.777 & 1.601 \\
\hline Low-level youth offender & 25941 & 0.073 & 0.751 & 28.739 & 1.576 \\
\hline Serious youth offender & 1228 & 0.004 & 0.759 & 27.907 & 1.571 \\
\hline Low-level persister & 52664 & 0.149 & 0.691 & 28.520 & 1.443 \\
\hline Serious persister & 18165 & 0.051 & 0.680 & 26.645 & 1.393 \\
\hline Total & 354354 & 1 & 0.739 & 29.432 & 1.565 \\
\hline
\end{tabular}

Source: Own calculation on data from Statistics Denmark.

Notes: Low-level: No incarceration. Persister: Convicted after age 21.

a: Median age only calculated among those who become fathers before age 45 . 
TABLE 2 Number of children and unique fertility partners across criminal justice history for Danish men born 1965-1973 conditional on fatherhood

Group

Number of children conditional on fatherhood

Number of unique fertility partners conditional on fatherhood

Law-abiding or non-sanctioned

2.13

1.10

Low-level youth offender

2.10

1.16

Serious youth offender

2.07

1.17

Low-level persister

2.09

1.24

Serious persister

2.05

1.36

Source: Own calculation on data from Statistics Denmark.

Notes: Low-level: No incarceration. Persister: Convicted after age 21. Median age only calculated among those who become fathers before age 45 . 
TABLE 3 Expected and counterfactual second-generation offending assuming equal transmission of crime across first generation's criminal justice history

\section{Reference crime rate birth cohort for sons}

1988

1993

1998

1988

1993

2.40

1998

Retrospective Odds Ratio estimate

(Hjalmarsson and Lindquist 2012)

(Besemer et al. 2017)

A

Share of sons ever convicted $(S)$ at 30

.190

$.140^{\mathrm{a}}$
354354

261758

$.100^{\mathrm{b}}$

.190

$.140^{\mathrm{a}}$

354354

Number of fathers

.260

261758

Share of fathers convicted $\left(\mathrm{F}_{\mathrm{C}}\right)$

Share of fathers never convicted $\left(\mathrm{F}_{\mathrm{L}}\right)$

B Son's probability of ever convicted at age 30

Convicted father $\left(\mathrm{P}_{\mathrm{C}}\right)$

Non-convicted father $\left(\mathrm{P}_{\mathrm{L}}\right)$

$280 \quad .211$

.159

.740

.260

xpected number of sons convicted at age 30 under observed fertility rates ${ }^{c}$

Convicted man $\left(\mathrm{N}_{\mathrm{C}} * \mathrm{P}_{\mathrm{C}} * \mathrm{CFR}_{\mathrm{C}} * 0.5\right)$

Non-convicted man $\left(\mathrm{N}_{\mathrm{L}} * \mathrm{P}_{\mathrm{L}} * \mathrm{CFR}_{\mathrm{L}} * 0.5\right)$

$20,179 \quad 15,219$

15,219
23,593

32,621

Expected number of sons not convicted at age 30 under observed fertility rates ${ }^{c}$

\begin{tabular}{|c|c|c|c|c|c|c|}
\hline Convicted man $\left[\mathrm{N}_{\mathrm{C}} *\left(1-\mathrm{P}_{\mathrm{C}}\right) * \mathrm{CFR}_{\mathrm{C}} * 0.5\right]$ & 51,890 & 56,850 & 60,983 & 50,449 & 55,675 & 60,086 \\
\hline Non-convicted man $\left[\mathrm{N}_{\mathrm{L}} *\left(1-\mathrm{P}_{\mathrm{L}}\right) * \mathrm{CFR}_{\mathrm{L}} * 0.5\right]$ & 172,541 & 181,568 & 188,525 & 174,182 & 182,743 & 189,422 \\
\hline
\end{tabular}

Expected number of sons convicted at age 30 under counterfactual fertility rates ${ }^{c}$
Convicted man $\left(\mathrm{N}_{\mathrm{C}} * \mathrm{P}_{\mathrm{C}} * \mathrm{CFR}_{\mathrm{C}} * 0.5\right)$
21,960
16,562
12,065
23,528
17,840
13,041

Expected number of sons not convicted at age 30 under counterfactual fertility rates ${ }^{c}$

Convicted man $\left.\left[\mathrm{N}_{\mathrm{C}} *\left(1-\mathrm{P}_{\mathrm{C}}\right) * \mathrm{CFR}_{\mathrm{L}} * 0.5\right)\right]$

$56,468 \quad 61,866$

66,363

54,899

60,587

65,387

D Counterfactual share of sons ever convicted at 30

.192

.142

.101

Percentage increase in criminal sons

$1.1 \%$

$1.1 \%$

$3.4 \% \quad 3.5 \%$

Percentage increase in non-criminal sons

$2.0 \%$

$2.1 \%$

$3.5 \%$

.192

.142

.101

Source: Own calculations on data from Statistics Denmark

${ }^{\text {a }}$ Extrapolated to age 30 from the cumulative share at age 25 assuming similar relative trend as 1988 cohort. ${ }^{b}$ Extrapolated to age 30 from the cumulative

share at age 20 assuming similar relative trend as 1988 cohort. ${ }^{c}$ Assuming 50/50 gender split for offspring. 
TABLE 4 Expected and counterfactual second-generation offending assuming that all transmission of crime from first generation is through men who persist after turning 21

Reference crime rate birth cohort for sons

Retrospective Odds Ratio estimate

1988

Share of sons ever convicted $(S)$ at 30
Number of men (potential fathers)

Number of fathers

Share of fathers convicted after age $21\left(\mathrm{~F}_{\mathrm{C} 2}\right)$

Share of fathers desisting before $21\left(\mathrm{~F}_{\mathrm{Cl}}\right)$

Share of fathers never convicted $\left(\mathrm{F}_{\mathrm{L}}\right)$

B Son's probability of ever convicted at age 30

Convicted father who persist $\left(\mathrm{P}_{\mathrm{C}^{*}}\right)$

Convicted father who desist $\left(\mathrm{P}_{\mathrm{L}}\right)$

Non-convicted father $\left(\mathrm{P}_{\mathrm{L}}\right)$

C Expected number of sons convicted at age 30 under observed fertility rates

Convicted after age $21 \mathrm{man}\left(\mathrm{N}_{\mathrm{C}_{2}} * \mathrm{P}_{\mathrm{C}^{*}} * \mathrm{CFR}_{\mathrm{C} 2} * 0.5\right)$

Convicted, desisting $\left(\mathrm{N}_{\mathrm{C} 1} * \mathrm{P}_{\mathrm{L}} * \mathrm{CFR}_{\mathrm{C} 1} * 0.5\right)$

Non-convicted or man $\left(\mathrm{N}_{\mathrm{L}} * \mathrm{P}_{\mathrm{L}} * \mathrm{CFR}_{\mathrm{L}} * 0.5\right)$

Expected number of sons not convicted at age 30 under observed fertility rates ${ }^{c}$

Convicted after age $21 \mathrm{man}\left[\mathrm{N}_{\mathrm{C}}\left(1-\mathrm{P}_{\mathrm{C}}\right) * \mathrm{CFR}_{\mathrm{C} 2} * 0.5\right]$

Convicted, desisting $\left[\mathrm{N}_{\mathrm{C} 2} *\left(1-\mathrm{P}_{\mathrm{L}}\right) * \mathrm{CFR}_{\mathrm{C} 2} * 0.5\right] \quad 18,013$

Non-convicted man $\left[\mathrm{N}_{\mathrm{C} 1} *\left(1-\mathrm{P}_{\mathrm{L}}\right) * \mathrm{CFR}_{\mathrm{L}} * 0.5\right]$

Expected number of sons convicted at age 30 under counterfactual fertility rates ${ }^{c}$

Convicted after age 21 man $\left(\mathrm{N}_{\mathrm{C} 2} * \mathrm{P}_{\mathrm{C} *} * \mathrm{CFR}_{\mathrm{L}} * 0.5\right) \quad 18,746$

Convicted, desisting $\left[\mathrm{N}_{\mathrm{C} 2} *\left(1-\mathrm{P}_{\mathrm{L}}\right) * \mathrm{CFR}_{\mathrm{L}} * 0.5\right]$

Expected number of sons not convicted at age 30 under counterfactual fertility rates ${ }^{c}$

Convicted after age 21 man $\left.\left[\mathrm{N}_{\mathrm{C} 2} *\left(1-\mathrm{P}_{\mathrm{C}}\right) * \mathrm{CFR}_{\mathrm{L}} * 0.5\right)\right] \quad 37,939$

Convicted, desisting $\left[\mathrm{N}_{\mathrm{C} 2} *\left(1-\mathrm{P}_{\mathrm{L}}\right) * \mathrm{CFR}_{\mathrm{L}} * 0.5\right]$

D Counterfactual share of sons ever convicted at 30

$\% \Delta$ between expected share and counterfactual share

Percentage increase in criminal sons per man

Percentage increase in non-criminal sons per man

Source: own calculations on data from Statistics Denmark.

${ }^{\text {a }}$ Extrapolated to age 30 from the cumulative share at age 25 assuming similar relative trend as 1988 cohort. ${ }^{b}$ Extrapolated to age 30 from the cumulative share at age 20 assuming similar relative trend as 1988 cohort. $^{c}$ Assuming 50/50 gender split for offspring.

8

.190

172,636

\begin{abstract}
3,447
\end{abstract}

$$
2.06
$$

1998

1988

1993

2.40

1998

Besemer et al. 2017)

$\begin{array}{cc}.140^{\mathrm{a}} & .100^{\mathrm{b}} \\ 354354 & \\ 261758 & \\ .183 & \\ .077 & \\ .740 & \end{array}$

.190

$.140^{\mathrm{a}}$

354354

261758

.183

.077

.740

$.331 \quad .252$

.185

.081

.081

.277

.109
109

.204

.115
.115

.151

.109

.077

75,754

$\begin{array}{ccccc}12,757 & 9,351 & 18,369 & 15,725 & 10,341 \\ 2,462 & 1,736 & 3,241 & 2,376 & 1,642 \\ 23,593 & 16,636 & 31,064 & 22,418 & 15,740 \\ & & & & \\ 37,905 & 41,312 & 32,293 & 36,608 & 40,321 \\ 18,945 & 19,671 & 18,166 & 19,068 & 19,765 \\ 181,568 & 188,525 & 174,098 & 182,743 & 189,422\end{array}$

181,568

14,274
2,500

188,525

0,552

$10,462 \quad 20,552 \quad 15,725 \quad 11,571$

2,5

42,411

46,2

46,222
19,980

$\begin{array}{cc}18,296 & 19,243 \\ .193 & .142 \\ 1.6 \% & 1.7 \% \\ 3.9 \% & 4.0 \%\end{array}$

$\begin{array}{cc}19,980 & 18,451 \\ .102 & .194 \\ 1.8 \% & 1.9 \% \\ 4.1 \% & 4.2 \%\end{array}$

36,132
18,451

40,959
19,367

45,114

$19,367 \quad 20,075$

$\begin{array}{cc}19,367 & 20,075 \\ .143 & .102 \\ 2.1 \% & 2.2 \%\end{array}$

$\begin{array}{llll}.102 & .194 & .143 & .102 \\ 1.8 \% & 1.9 \% & 2.1 \% & 2.2 \% \\ 4.1 \% & 4.2 \% & 4.4 \% & 4.5 \% \\ 2.1 \% & 1.8 \% & 2.0 \% & 2.0 \%\end{array}$


Table 5 Comparing retrospective and prospective odds ratios

Hjalmarsson and Besemer et al. (2017)

Lindquist (2012)

Birth cohort

$\begin{array}{llllll}1988 & 1993 & 1998 & 1988 & 1993 & 1998\end{array}$

Retrospective OR estimate

$\begin{array}{llllll}2.06 & 2.06 & 2.06 & 2.40 & 2.40 & 2.40\end{array}$

Prospective OR estimate, all fathers

2.03

2.02

2.02

2.38

2.36

2.36

Prospective OR estimate, all men

1.78

1.81

$\begin{array}{lll}1.84 & 2.05 & 2.10\end{array}$

2.13 
FIGURE 1 Group taxonomy conditional on type of sentence and age at last conviction

$\begin{array}{lcc}\text { No criminal } & \text { Last } & \text { Last } \\ \text { convictions } & \begin{array}{c}\text { conviction } \\ \text { before 21 }\end{array} & \text { conviction } \\ \text { at/after } 21\end{array}$

Never
incarcerated

Ever

incarcerated

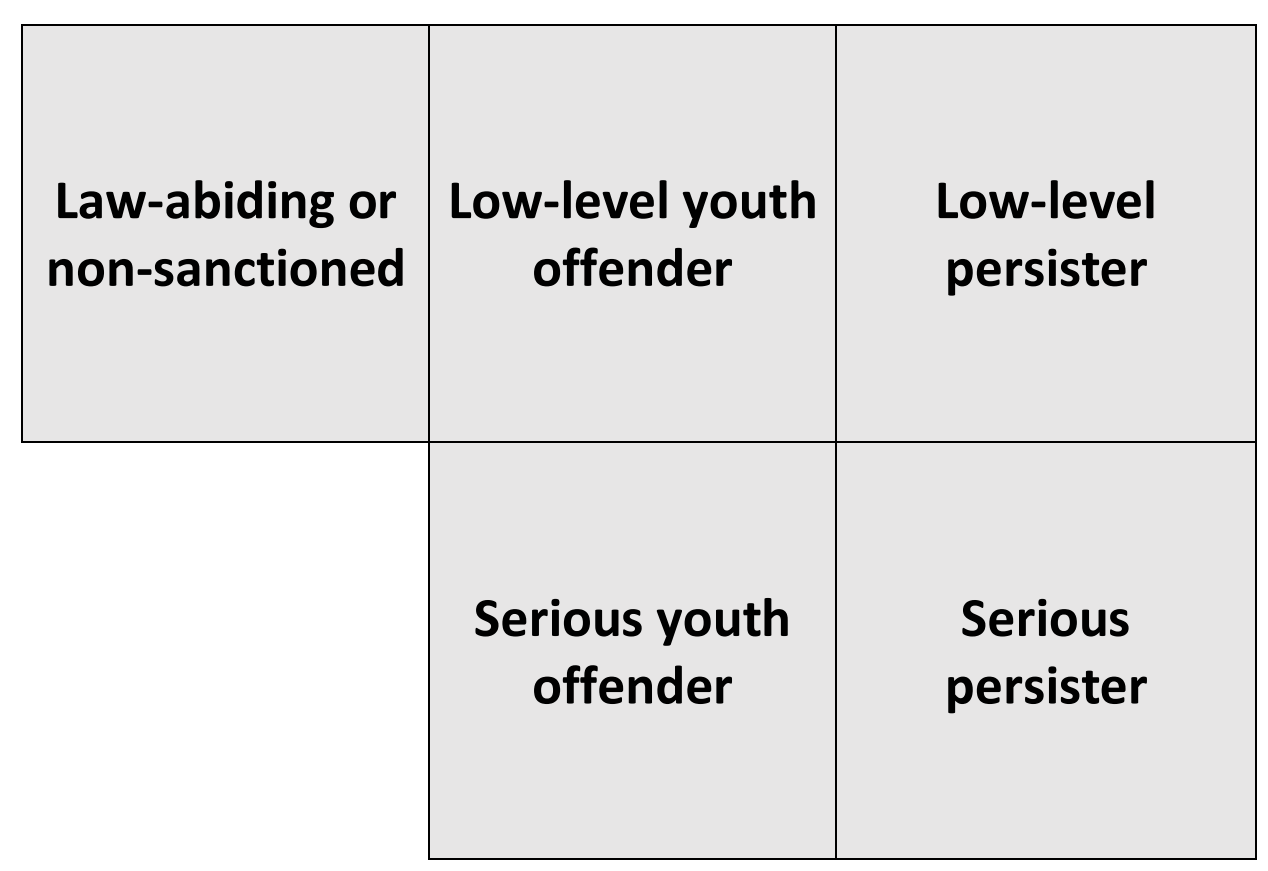


FIGURE 2 Kaplan-Meyer curves for the transition to fatherhood conditional on criminal justice history for Danish men born 1965-1973

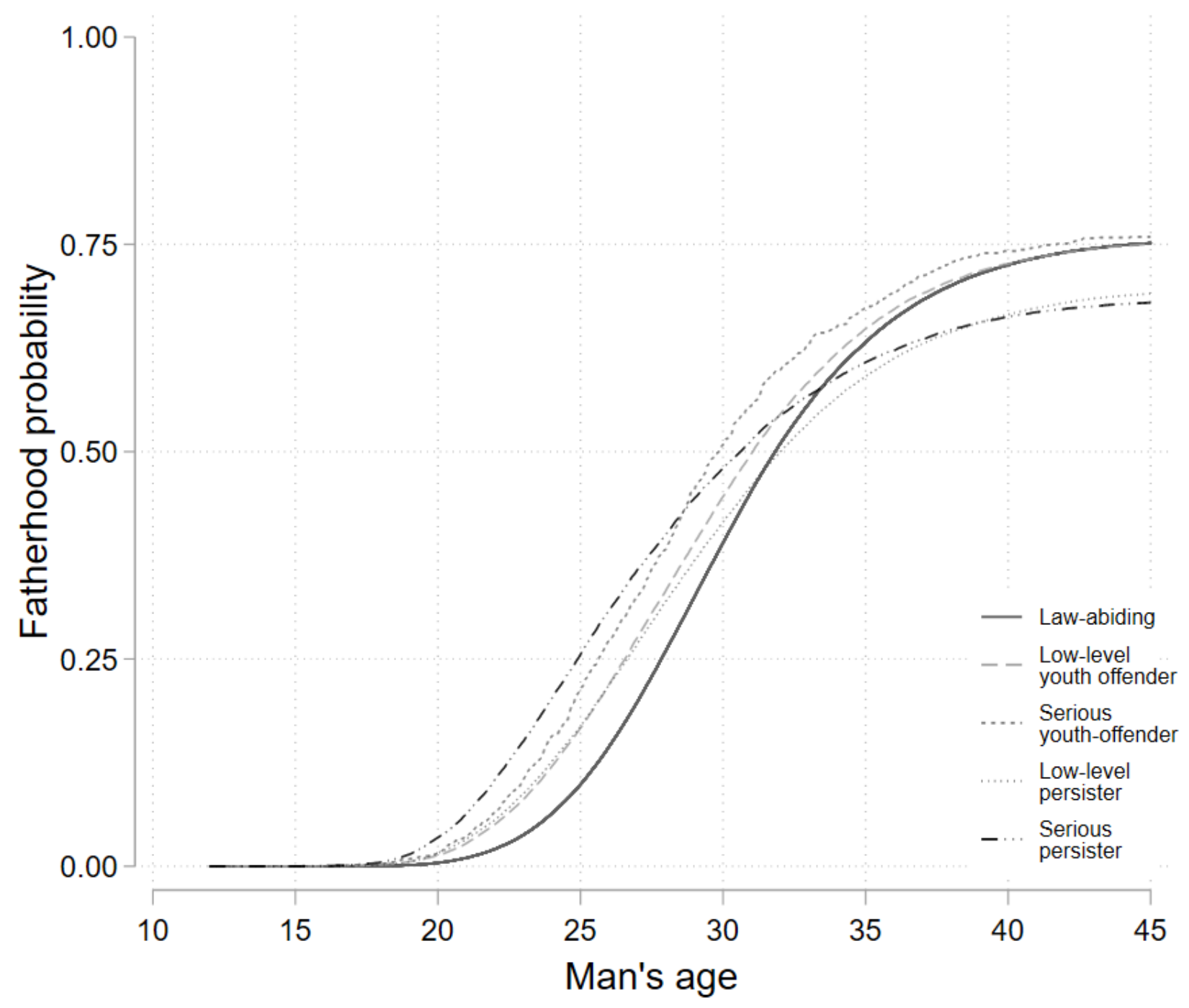

Source: Own calculation on data from Statistics Denmark.

Notes: Notes: Low-level: No incarceration. Persister: Convicted after age 21. Median age only calculated among those who become fathers before age 45 . 
FIGURE 3 Completed cohort fertility across age conditional on criminal justice history for Danish men born 1965-1973

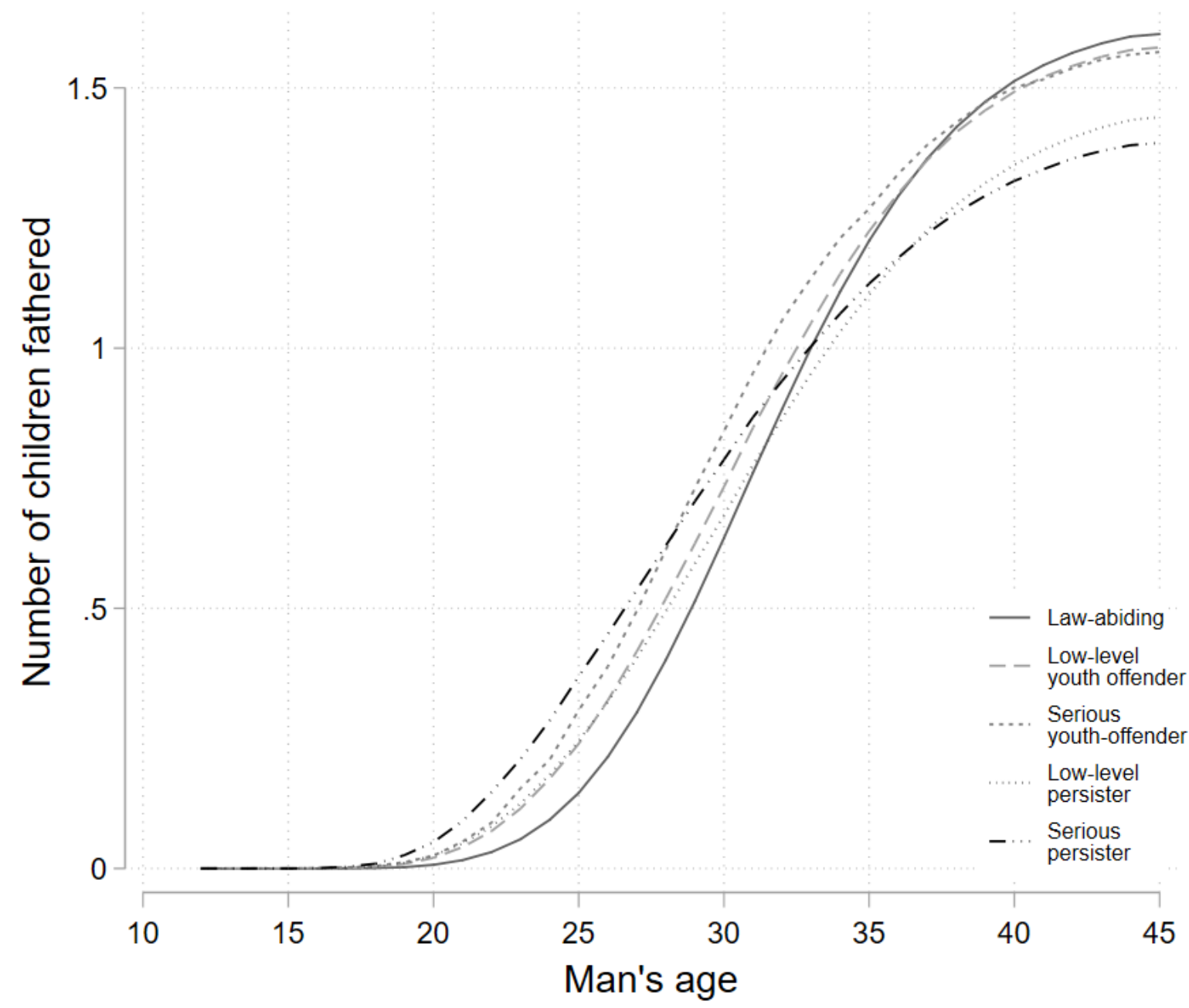

Source: Own calculation on data from Statistics Denmark.

Notes: Notes: Low-level: No incarceration. Persister: Convicted after age 21. Median age only calculated among those who become fathers before age 45 . 
7 APPENDIX A: 
FIGURE A1 Kaplan-Meyer curves with confidence intervals for the transition to fatherhood conditional on criminal justice history for Danish men born 1965-1973

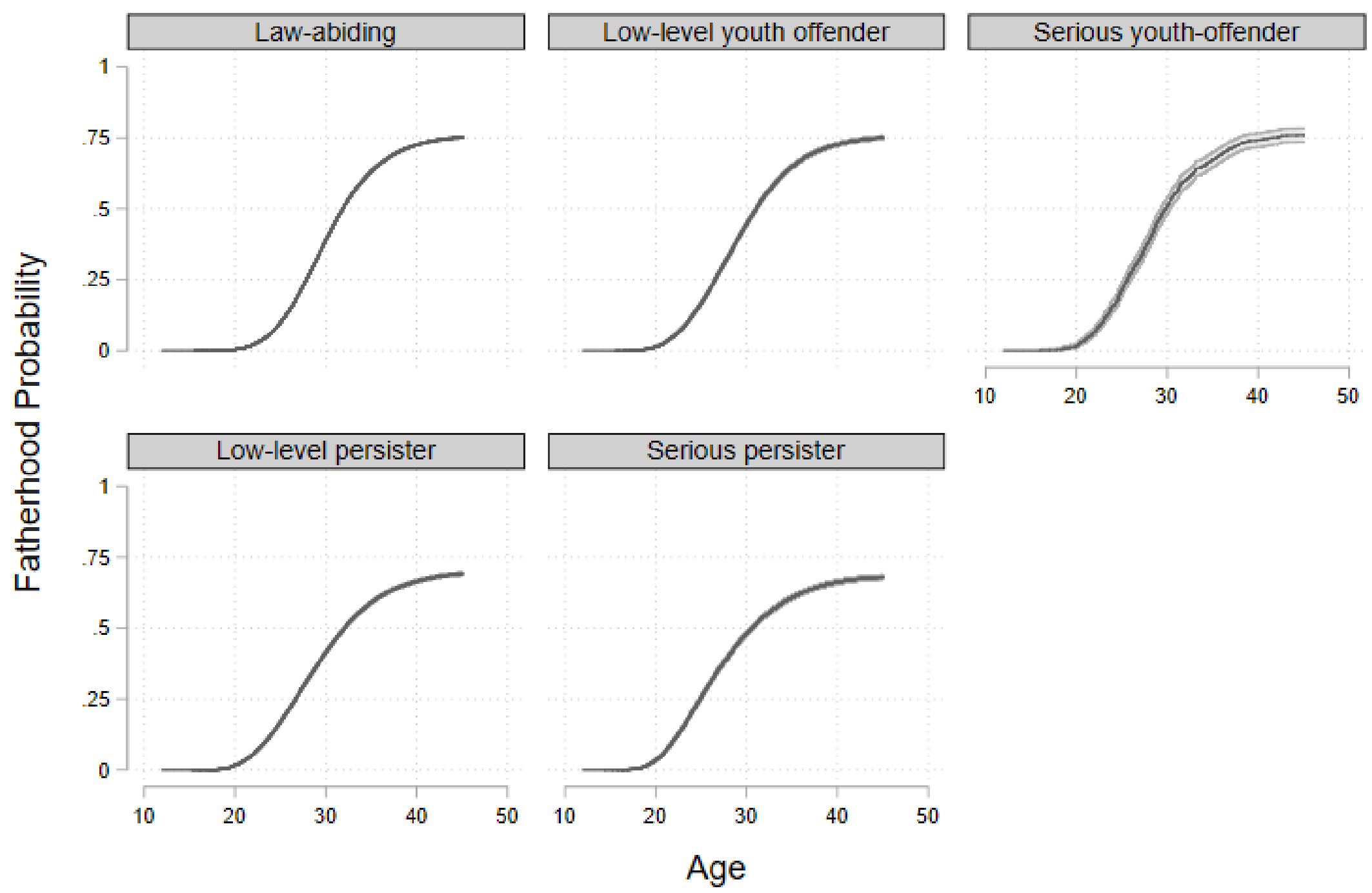

Source: Own calculation on data from Statistics Denmark. 


\section{APPENDIX B: DERIVATION EXAMPLE}

OR: $\frac{\frac{P_{C}}{1-P_{C}}}{\frac{P_{L}}{1-P_{L}}}=2.06 \quad$ (Hjalmarsson and Lindquist 2012)

$\mathrm{P}_{\mathrm{C}}$ : Probability of CJ contact if father had CJ contact

$\mathrm{P}_{\mathrm{L}}$ : Probability of $\mathrm{CJ}$ contact if father did not have $\mathrm{CJ}$ contact

It follows that $1>P_{C}>P_{L}>0$

Share of sons exposed to fathers with CJ contact: $F_{C J}=.26$ (Table 1, assuming identical gender distribution of children across fathers' $\mathrm{CJ}$ contacts)

Expected share of sons with CJ contact $S_{C J}=.19$ (1988 cohort at age 30 cf. Statistics Denmark)

$$
\begin{aligned}
& S_{C J}=.19=.74 * P_{L}+.26 * P_{C} \\
& \leftrightarrow \\
& P_{C}=\frac{.19-.74 * P_{L}}{.26} \\
& \downarrow \\
& \frac{\frac{.19-.74 * P_{L}}{.26}}{1-\frac{.19-.74 * P_{L}}{.26}}=2.06 \\
& \leftrightarrow \quad \frac{P_{L}}{1-P_{L}} \\
& P_{L}=\frac{\sqrt{1.7501}-1.0742}{1.5688} \approx .159 \\
& P_{C}=\frac{.17-.74 * .12}{.26} \approx .280
\end{aligned}
$$

